\title{
Theoretical and quantitative analysis of cyanosis colouration in newborn
}

\author{
Nur Fatihah Azmi ${ }^{1}$, Loe Feijs ${ }^{2}$, Frank Delbressine ${ }^{2}$ \\ ${ }^{1}$ Centre for Telecommunication Research and Innovation (CeTRI), Fakulti Kejuruteraan Elektronik Dan Kejuruteraan Komputer \\ (FKEKK), Universiti Teknikal Malaysia Melaka (UTeM), Melaka, Malaysia \\ ${ }^{2}$ Future Everyday, Department of Industrial Design, Eindhoven University of Technology, Eindhoven, The Netherlands
}

\begin{tabular}{l}
\hline \hline Article Info \\
\hline Article history: \\
Received Jul 25, 2021 \\
Revised Nov 15, 2021 \\
Accepted Dec 28, 2021
\end{tabular}

\section{Keywords:}

Baby simulation

CIELAB

CIE 1931 xy

Colour changing actuator

Colour quantification

Cyanosis

\begin{abstract}
This paper investigate the occurrence of cyanosis's blue colouration in newborn babies with the focused on a detailed version of the oxyhaemoglobin's $\left(\mathrm{HbO}_{2}\right)$ and deoxyhaemoglobin's $(\mathrm{Hb})$ transmission and reflectance spectrum in the vessel. A quantitative analysis of cyanosis colour is based on the cyanotic skin observer model. The proposed method formed a basis work of colour changes to implement in the future cyanosis baby manikin for baby simulation. A series of transfer functions described by the relationship of the light propagation in human skin. Results showed that the colouration of $\mathrm{HbO}_{2}$ is less saturated compared to $\mathrm{Hb}$ and its depends on the $\mathrm{HbO}_{2}$ 's and $\mathrm{Hb}$ 's reflectance spectrum in the blood. Meaning that, the correct International Commission on Illumination (CIE) $\mathrm{L}^{*} \mathrm{a}^{*} \mathrm{~b}^{*}$ colour values of cyanosis in real newborn babies will be quantified and later to be implemented in a baby manikin. Despite of non-experimental methodology implemented, it is based on putting together knowledge from literature. In particular, the database of the absorbance spectra of $\mathrm{HbO}_{2}$ and $\mathrm{Hb}$ and the three-cone pigments with different absorption spectra of the colour receptors in the human retina. The results of newborn's cyanosis colour was obtained and determined both in a two-dimensional International Commission on Illumination (CIE) $1931 x y$ and a three-dimensional CIE L*a ${ }^{*} b^{*}$.
\end{abstract}

This is an open access article under the CC BY-SA license.

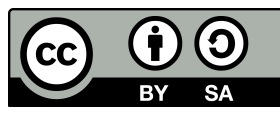

\section{Corresponding Author:}

Nur Fatihah Azmi

Centre for Telecommunication Research and Innovation (CeTRI)

Fakulti Kejuruteraan Elektronik Dan Kejuruteraan Komputer (FKEKK)

Universiti Teknikal Malaysia Melaka (UTeM)

Hang Tuah Jaya, 76100 Melaka, Malaysia

Email: fatihah@utem.edu.my

\section{INTRODUCTION}

Training new medical practitioners (doctors, nurses, and midwives), especially in critical life-threatening situations, requires numerous skills to understand and carry out an appropriate prevention and treatment strategy in saving babies' lives. Generally, simulation can be defined as a teaching method used by medical educators to enhance learning in various healthcare contexts. The researchers in the Netherlands, has started the non-invasive research on perinatal monitoring which focused on the healthcare of the expectant mother and newborn baby, pre and post delivery [1]. More recently, the topic of simulation manikins focusing on neonatology has been explored by Peters P. the preterm baby simulator was designed by to be used for the training of neonatologists and nurses [2]. Later in 2019, a researcher from the same lab invented the three-dimensional (3D) manikin for newborn life support (NLS) which intended at improving the NLS training [3]. While current 
baby simulators focused on emergency medicine and resuscitation courses, the realism of cyanosis colouration in a baby simulator has not really been explored. As central cyanosis is a severe pathological sign in babies, new medical residents and medical practitioners have to master the skill to evaluate a central cyanosis precisely. Thus, a cyanosis neonatal simulator with a accurate colouration in precise region and correct timing of the colour change from cyanosis to non-cyanosis are good thing to have in a neonatal-patient simulator [4].

The Greek word, $\kappa v \alpha \nu \epsilon O \varsigma$ refers to cyanosis which means a darker blue purplish discolouration and can be seen in in the area of around the lips, fingers, and toes [5]. After birth, cyanosis is a common clinical finding in newborn infants and is caused by reduced arterial oxygen saturation. Newborn infants normally have cyanosis several minutes after birth and become pink when the oxygen saturation rises above $85 \%$. The observation of skin colour is one of the components the doctors and neonatologists will look for 1 to 5 minutes after birth using the Apgar scoring method [6]. A 5-minutes Apgar score of 7-10 indicates the baby's condition is good to excellent, a score of 4-6 is moderately below normal, and a score of 0-3 is critically low. When the blood contains a lack of oxygen, the skin colour shifts from intense-red to a dark blue colouration. The colour shifting causing the skin and lips seem to be blueish in colour. The cyanosis colourant is become more apparent by a dark-blue or purple discolouration of the tongue, mucous membranes and the mouth's area as in Figure 1 .

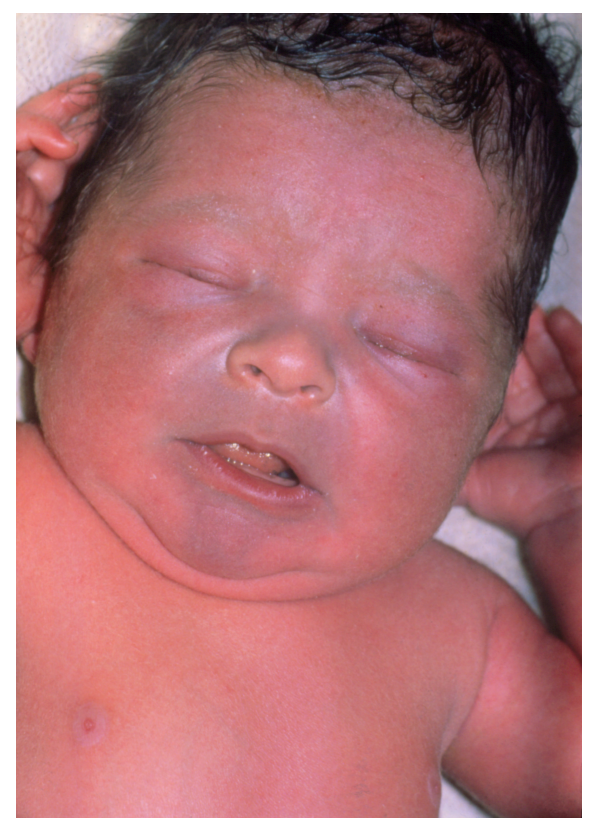

Figure 1. Infant suffering from cyanosis [7]

There are two states of haemoglobin; oxyhaemoglobin $\left(\mathrm{HbO}_{2}\right)$ and deoxyhaemoglobin, also known as deoxygenated haemoglobin $(\mathrm{Hb})$ [8]. Cyanosis is related to the Hb deficiency and disorders of abnormal haemoglobin. The amount of oxygen might not be sufficient, resulting in respiratory distress such as cyanosis in a newborn [9]. The lack of $\mathrm{HbO}_{2}$ was measured by a pulse oximeter, a common medical device used for measuring the level of oxygen saturation [10] in the blood. When the reading of $\mathrm{SpO}_{2}$ is $85 \%$ or less, cyanosis becomes clinically overt [11], [12].

Cyanosis assessment in a newborn is highly abstract and the evaluation of cyanosis is challenging because of many aspects such as the environment's lighting colour and the intensity level and the effect of the coloured objects in the surrounding [13]. An observer model and the light propagation's series represented by the transfer functions in the block diagrams described a cyanosis occurrence in optical properties in skin layers of human was obtained and discussed as in Figure 2 and Figure 3 in the study of Azmi et al. [14]. The study demonstrated three different output lights which explained the light paths in humans' skin. Based on the transfer function obtained in the study of Azmi, a bluish cyanosis seen by the eyes can be modelled by quantifying the interaction between the light source, the transfer function of $\mathrm{HbO}_{2}$ and $\mathrm{Hb}$ and the observer's colour matching functions. This is how the colours are portrayed in the brain [15]. Fatihah et al. [16] had set up the experiment using the cyanosis observation lamp, the Philips Master LEDspot LED light (940 type lamp; Philips) as the 
source of the illuminant to measure the cyanosis colour values of their developed cyanosis manikin as the employed observation lamp was suggested the most suitable lamp to be used in the operating theater to assess cyanosis. While the cyanosis quantification in [14] is mostly based on the assumption and simplification, the details about the transmission spectra of $\mathrm{HbO}_{2}$ and $\mathrm{Hb}$ has not been extinsively investigated. Therefore, this paper aims to add the detailing of the transfer functions as an additional approach for cyanosis quantification and determination in International Commission on Illumination (CIE) $\mathrm{L}^{*} \mathrm{a}^{*} \mathrm{~b}^{*}$ colour values based on the $\mathrm{HbO}_{2}$ and $\mathrm{Hb}$ 's actual reflectance spectrum. In addition, the CIE $\mathrm{L}^{*} \mathrm{a}^{*} \mathrm{~b}^{*}$ values of skin the cyanotic and non-cyanotic skin will be evaluated.

\section{METHOD}

\subsection{Colour matching function and the D65 illuminant source}

Rods and cones are two forms of photoreceptors in the human retina that absorbs light. The three cones are long $(\mathrm{L})$, medium $(\mathrm{M})$, and short $(\mathrm{S})$-wavelength cones and they ara contributing in seeing colours. The CIE tristimulus values of $\bar{X}_{10}, \bar{Y}_{10}$, and $\bar{Z}_{10}$ are the theoretical expression of the chromatic response of the $10^{\circ}$ standard observer. The values depend on the spectral sensitivity curves, which are known as the CIE standard observer [17]. For this study, the numerical data of spectral response curves corresponding to the CIE 1964 meaning was downloaded from [18] and a sampling at $2 \mathrm{~nm}$ stepsize of $(\lambda)$ between $370 \mathrm{~nm}$ and $780 \mathrm{~nm}$ was performed. Figure 2(a) associates with the CIE colour matching in $10^{\circ}$ standard observer. Each functions denoted by $\bar{X}_{10}, \bar{Y}_{10}$, and $\bar{Z}_{10}$ which is referred to the colour matching functions of red, green and blue, respectively.

An illuminant is an emission with a relative spectral power distribution versus wavelength definition [19]. The cyanosis detection could be affected by lighting colour and the surrounding [20]. The simplifying assumption was made by employing a daylight D65 illuminant to simulate cyanosis and non-cyanosis colour's measurement for convenience and reproducibility as in Figure 2(b). The illuminant D65 database is downloadable from RIT useful color data [21] which a sampling of $2 \mathrm{~nm}$ stepsize between $370 \mathrm{~nm}$ and $780 \mathrm{~nm}$ were taken.
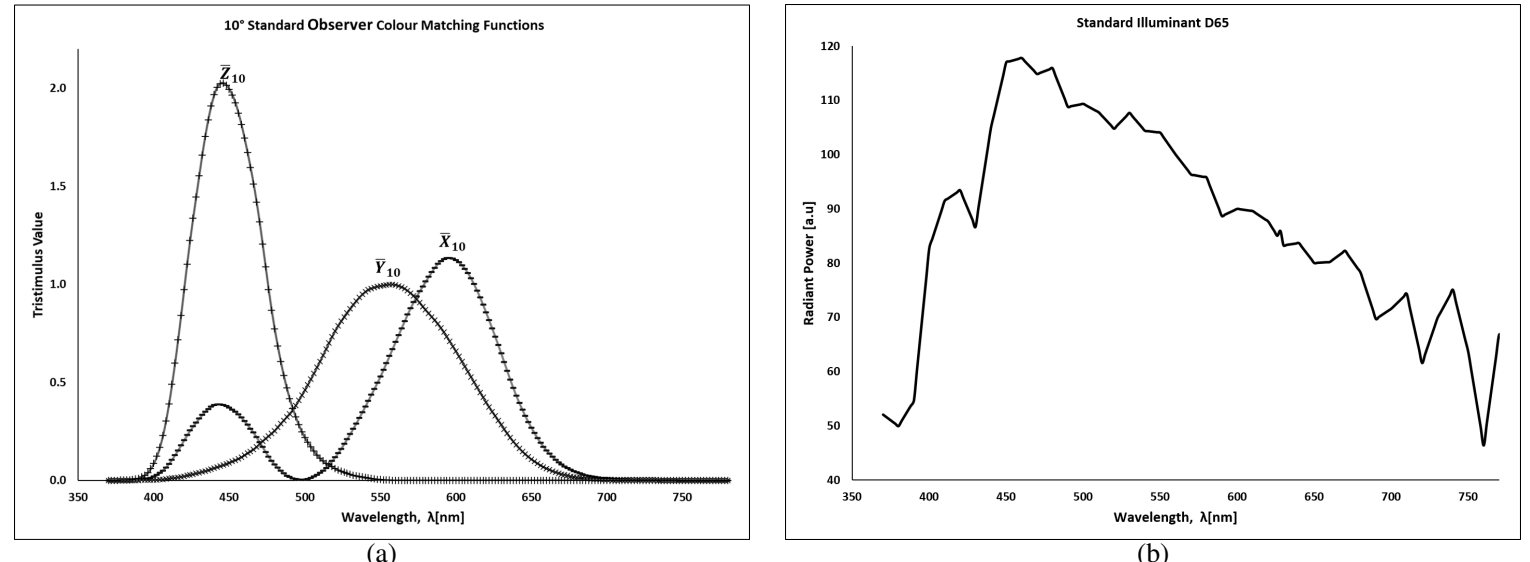

Figure 2. Spectral response curves and illuminant employed in the study of (a) spectral response curves and (b) spectral distribution of D65 illuminant

\subsection{The $\mathrm{HbO}_{2}$ and $\mathrm{Hb}$ 's transmission spectra}

The combination of selective absorption and scattering of some light wavelengths will determine the colour of the skin. As for cyanosis skin colouration, the dermis' absorption properties are dominantly determined by $\mathrm{HbO}_{2}$ and $\mathrm{Hb}$ [22]. The tabulated molar extinction coefficient, $\varepsilon$ in $\mathrm{cm}^{-1} /($ moles/liter) for $\mathrm{HbO}_{2}$ and $\mathrm{Hb}$ were downloaded from [23] and a sampling of $2 \mathrm{~nm}$ were obtained between 370 and $780 \mathrm{~nm}$. The calculation of the absorbance assumes a path length determined by a cuvette of $1 \mathrm{~cm}$ and $x$ is $150 \mathrm{~g} \mathrm{Hb} / \mathrm{liter}$ but the light travels back and forth in the baby's blood vessel not in the cuvettes. As a simplifying assumption a path length of $1 \mathrm{~mm}$ was utilized. So, now the $A$ is resulting from (1): 


$$
A=\frac{\varepsilon\left[L \cdot \mathrm{mol}^{-1} \cdot \mathrm{cm}^{-1}\right] \times 150[\mathrm{~g} / \mathrm{L}] \times P L}{64500\left[\mathrm{~g} \cdot \mathrm{mol}^{-1}\right]}
$$

where 64,500 is the gram molecular weight of $\mathrm{HbO}_{2}$ and path length, $P L=0.1$. Essentially this is Beer's law which says that attenuation is proportional to path length and concentration, the constant of proportionality being $\varepsilon$. Here $A$ denotes the absorbance, which is equal to $\varepsilon \times \mathrm{c} \times P L$, where $\varepsilon$ is a molar absorptivity, $\mathrm{c}$ is the concentration, and $P L$ is a path length.

The colouration of cyanosis can be quantified from the transmission spectra of the $\mathrm{HbO}_{2}$ and $\mathrm{Hb}$. From the absorption spectra of $\mathrm{HbO}_{2}$ and $\mathrm{Hb}$, the transmission of both spectral can be found by Beer's law as indicated in (1). The transmission of $\mathrm{HbO}_{2}$ and $\mathrm{Hb}$ can be formulated by the inverse relationship of the absorbance. The absorbance ranges from 0 to 2 is corresponding to a light transmittance ranging from 100\% to $1 \%$. At 0 absorbance unit, it means that no light of that particular wavelength has been absorbed, or $100 \%$ transmittance. On the other hand, absorbance equal to 1 and 2 means only $10 \%$ and $1 \%$ of light has been transmitted. The earlier paragraph mentioned the baby's blood vessel's and as a simplifying assumption, a path length of $1.0 \mathrm{~mm}$ was obtained. For this study where the path length of the baby's blood vessel's is unknown, the study by Yelda Pinar et al. was referred where the anatomical of the blood supply in the perioral region of 25 male adults from Turkey was examined [24]. The research revealed the external diameter of the superior labial artery (SLA) was averaged at $1.6 \mathrm{~mm}$ (min-max: $0.6-2.8 \mathrm{~mm}$ ) from its origin. Therefore, as a basis of the absorption and transmission calculation in $\mathrm{HbO}_{2}$ and $\mathrm{Hb}$, a path length, $P L$ of $0.5 \mathrm{~mm}$ and $1.0 \mathrm{~mm}$ were attained. Figure 3 (a) and (b) depict the obtained plots for absorption (primary vertical-axis) and transmission (secondary vertical-axis) spectral from the above- mentioned path lengths. The $\mathrm{HbO}_{2}$ and $\mathrm{Hb}$ absorption spectrum are in a stepsize of $2 \mathrm{~nm}$ ranging from $\lambda=300 \mathrm{~nm}$ to $\lambda=700 \mathrm{~nm}$.

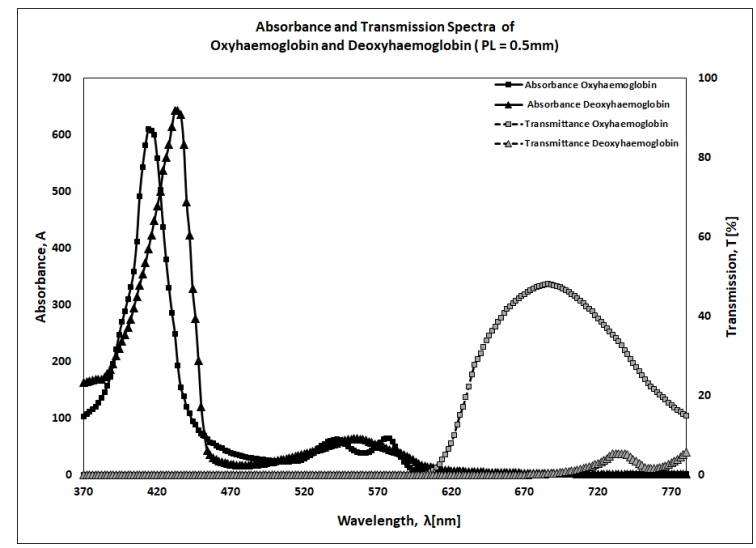

(a)

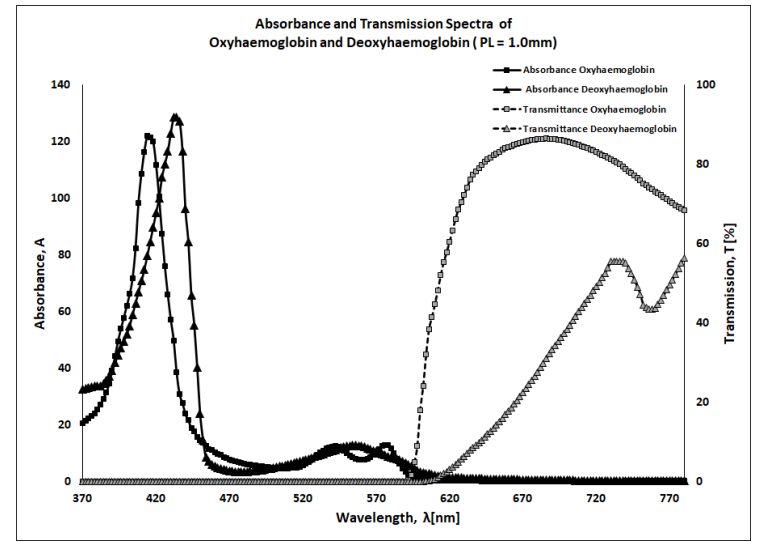

(b)

Figure 3. Absorption and transmission spectra of $\mathrm{HbO}_{2}$ and $\mathrm{Hb}$ with (a) path length, $\mathrm{PL}=0.5 \mathrm{~mm}$ and (b) path length, PL=1.0 mm

For the absorbance as a function of wavelength for $\mathrm{HbO}_{2}$, Figures 3 a) and (b) show that, at the short wavelength, more light was absorbed compared to in the long wavelength. Here, Figures 3 a) and (b) denote that $\mathrm{HbO}_{2}$ absorbs blue light more strongly than red (absorption peak at approximately $420 \mathrm{~nm}, 540 \mathrm{~nm}$, and $570 \mathrm{~nm}$ ) hence giving "more" red colour of blood in comparison with the Hb. On the other hand, for the transmission as a function of wavelength, the zero transmittance at the wavelengths less than $600 \mathrm{~nm}$ indicating Hb's absorption is small.

The transmissivities of $\mathrm{HbO}_{2}$ and $\mathrm{Hb}$ under different path length levels have also been plotted in Figures 3 (a) and (b). The transmission spectra of $\mathrm{HbO}_{2}$ peaks at $680 \mathrm{~nm}$ when path length is at PL=1.0 $\mathrm{mm}$. The transmission spectra of $\mathrm{Hb}$ when the $P L=1.0 \mathrm{~mm}$ had an optimum percentage of $59 \%$, which accounts for the colourimetric difference between $\mathrm{HbO}_{2}$ and $\mathrm{Hb}$. With a longer path length, the light has to travel through a longer path of the blood and hit many more main chromophores in the blood before been absorbed. This would make the increase in absorbance increase and make the blood appear darker in colour. 


\subsection{The tristimulus values measurement of $\mathrm{HbO}_{2}$ and $\mathrm{Hb}$}

Figures 4 (a), (b) and (c) show how the determination of tristimulus values $X, Y$ and $Z$, respectively, happens in $\mathrm{HbO}_{2}$ and $\mathrm{Hb}$ when the path length is $1.0 \mathrm{~mm}$. All above- mentioned figures are obtained as follows. The incoming light with D65 spectral distribution as referred in Figure 2(b) reflected the $\mathrm{HbO}_{2} \mathrm{Hb}$ and CIE colour matching functions with the spectral response in Figure 2(a). The spectral response then divides the incoming light into the region of a wavelength which refers to the red, green and blue colour and later was multiplied with the D65 function for each wavelength with the colour sensitivity function, and the transmission function. For example, to get the contributions of $\mathrm{X}_{\mathrm{Hb}}$, the colour sensitivity function for red was attained (in Figure $4 \mathrm{a}$ labeled as $\bar{X}_{10}$, dotted with '-') and take Hb's transmission function, thus contributed $\mathrm{X}_{\mathrm{Hb}}$ for each wavelength, $(\lambda)$. These are summed over the entire range of wavelengths. Thus, the output of the tristimulus values $(X, Y$, and $Z)$ was acquired.

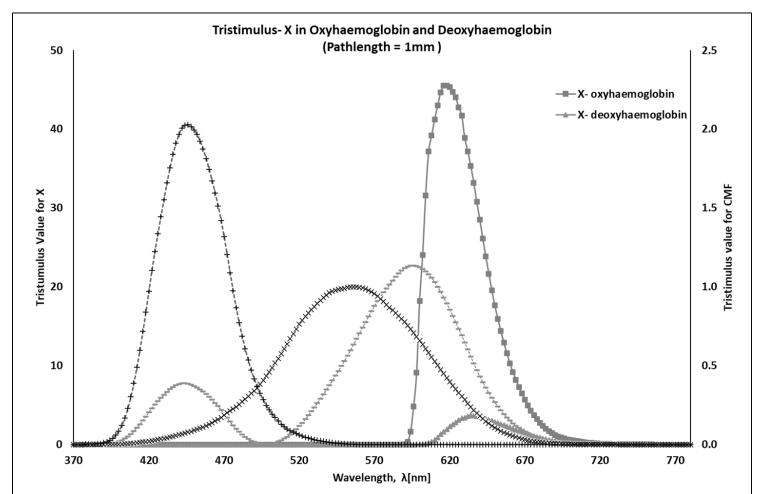

(a)

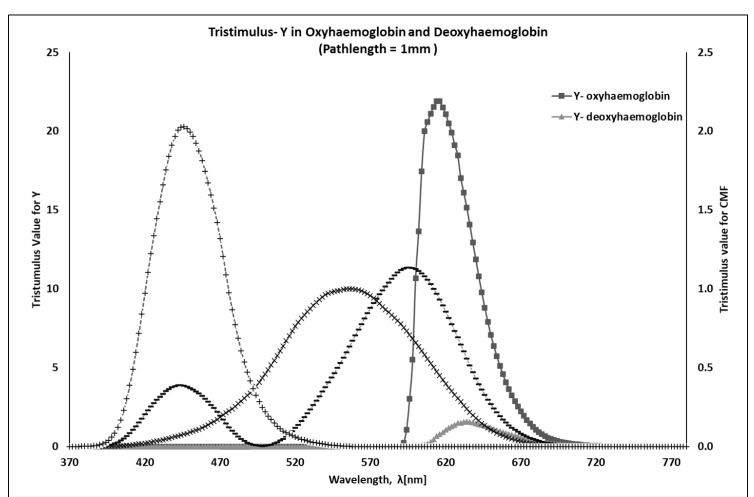

(b)

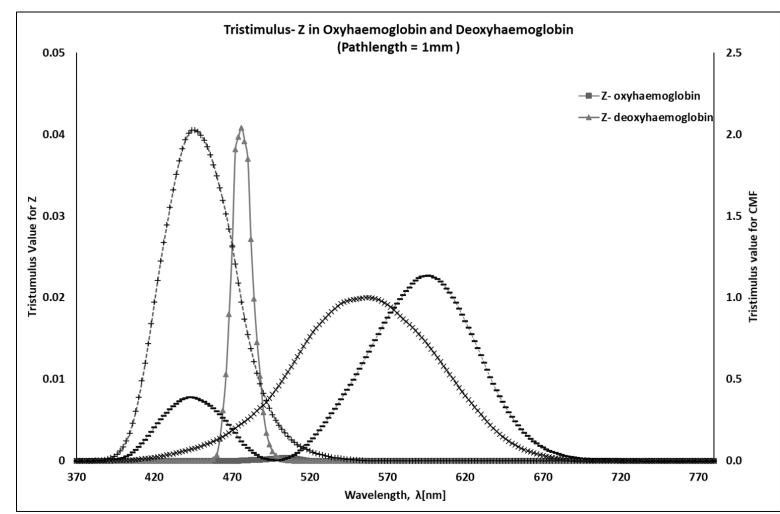

(c)

Figure 4. Tristimulus values $X, Y$ and $Z$ in $\mathrm{HbO}_{2}$ and $\mathrm{Hb}$ versus colour matching function: (a) tristimulus-X determination, (b) tristimulus- $Y$ determination, and (c) tristimulus- $Z$ determination

Here, the $(x, y, z)$ chromaticity coordinates can be quantified from the $(X, Y, Z)$ tristimulus values' as follows [24]:

$$
x=\frac{X}{X+Y+Z}, \quad y=\frac{Y}{X+Y+Z}, \quad z=\frac{Z}{X+Y+Z}
$$

The calculated chromaticity coordinates $(x, y, z)$ for $\mathrm{HbO}_{2}$ and $\mathrm{Hb}$ at $1.0 \mathrm{~mm}$ path length are $(0.6850,0.3149$, $2.683 \mathrm{E}-06)$ and $(0.7018,0.2955,0.0026)$, respectively.

\section{RESULTS}

As for the next step, the accurate determination of cyanotic (deoxygenated blood) and non-cyanotic (oxygenated blood) colour values and colour differences have been made in CIE L*a* b* colour system, resem- 
bling the way the human eye and the rest of the human visual system see colour differences using the following formulas. The coordinate of $\mathrm{L}^{*} \mathrm{a}^{*} \mathrm{~b}^{*}$ are formulated from the stimulus of light of $X, Y, Z$ and the white point of $X_{10}, Y_{10}, Z_{10}$. In this colour wheel, $\mathrm{L}^{*}$ indicates lightness and $\mathrm{a}^{*}$ and $\mathrm{b}^{*}$ indicate the chromaticity coordinates, with $\mathrm{a}^{*}$ is in the order of red $(+100)$ to green $(-100)$ axis while $\mathrm{b}^{*}$ is in the order of yellow $(+100)$ to blue $(-100)$ [25].

\section{DISCUSSIONS}

\subsection{Quantification and evaluation on the CIE $\mathrm{L}^{*} \mathrm{a}^{*} \mathrm{~b}^{*}$ values of $\mathrm{HbO}_{2}$ and $\mathrm{Hb}$}

The colour values of $\mathrm{HbO}_{2}$ and $\mathrm{Hb}$ can be exhibited in the $\mathrm{L}^{*} \mathrm{a}^{*} \mathrm{~b}^{*}$ three-dimensional colour space as shown in Figure 5 for the path length of $P L=0.5 \mathrm{~mm}$ and Figure 6 for $1.0 \mathrm{~mm}$ path length, both are display in $\mathrm{a}^{*} \mathrm{~b}^{*}$ plane. From the calculation, during the $0.5 \mathrm{~mm}$ path length, the CIE $\mathrm{L}^{*} \mathrm{a}^{*} \mathrm{~b}^{*}$ values for $\mathrm{HbO}_{2}$ and $\mathrm{Hb}$ are $(42.86,68.11,57.15)$ and $(20.43,42.25,28.27)$, respectively. When $P L=1.0 \mathrm{~mm}, \mathrm{CIE} \mathrm{L} \mathrm{a}^{*} \mathrm{~b}^{*}$ values for $\mathrm{HbO}_{2}$ and $\mathrm{Hb}$ are $(37.44,61.83,51.86)$ and $(7.87,27.62,12.44)$, respectively. All the $\mathrm{L}^{*} \mathrm{a}^{*} \mathrm{~b}^{*}$ three-dimensional colour space figures were plotted using the CIE $\mathrm{L}^{*} \mathrm{a}^{*} \mathrm{~b}^{*}$ plotting template from [26].

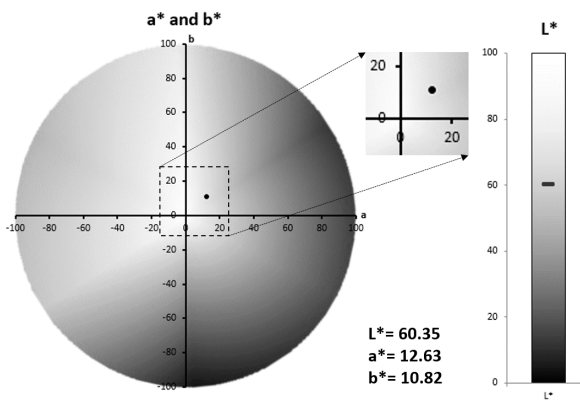

(a)

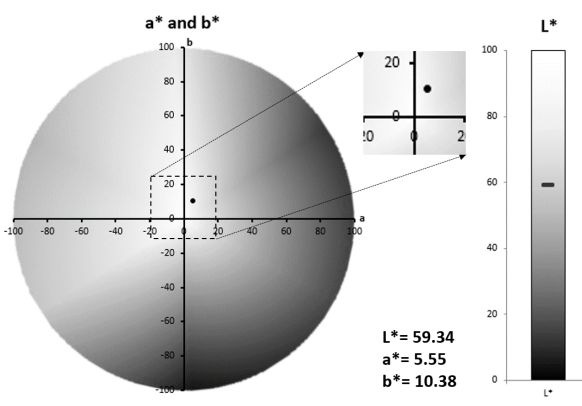

(b)

Figure 5. $\mathrm{a}^{*}$ and $\mathrm{b}^{*}$ chromaticity at $P L=0.5$ with (a) chromaticity plot for $\mathrm{HbO}_{2}$ and (b) chromaticity plot for $\mathrm{Hb}$

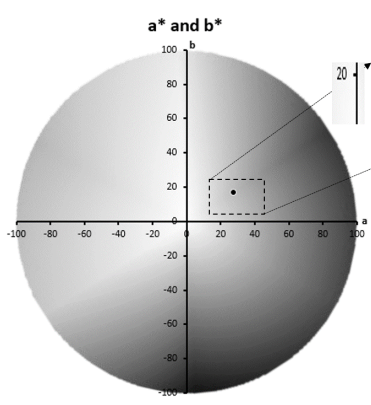

(a)

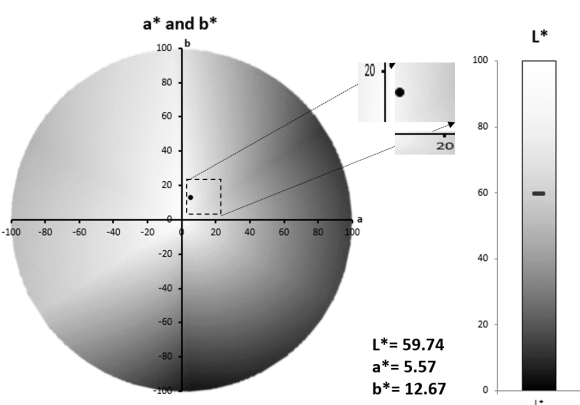

(b)

Figure 6. $\mathrm{a}^{*}$ and $\mathrm{b}^{*}$ chromaticity at $P L=1.0 \mathrm{~mm}$ with (a) chromaticity plot for $\mathrm{HbO}_{2}$ and (b) chromaticity plot for $\mathrm{Hb}$

Figure 5(a) and Figure 6(a), both $\mathrm{a}^{*}$ and $\mathrm{b}^{*}$ in $\mathrm{HbO}_{2}$ are between 61 to 68 and 51 to 58, respectively, referring to the point red hues. Furthermore, for the $\mathrm{L}^{*}$, it is approximately between 37 to 42 which is near 0 , so the colour is dark. On the other hand, the CIE $\mathrm{L}^{*} \mathrm{a}^{*} \mathrm{~b}^{*}$ for $\mathrm{Hb}$ is depicted in Figure 5 (b) and Figure 6(b). Both $\mathrm{a}^{*}$ and $\mathrm{b}^{*}$ are in the range of less red than $\mathrm{HbO}_{2}$ with $(42.25,28.27)$ and $(27.62,12.44)$, respectively. And for the $\mathrm{L}^{*}$, in both path lengths, the value is lower than the $\mathrm{L}^{*}$ for $\mathrm{HbO}_{2}$, where 20.43 for $0.5 \mathrm{~mm}$ and 7.87 for $1.0 \mathrm{~mm}$. The chromaticity values of $\mathrm{L}^{*} \mathrm{a}^{*} \mathrm{~b}^{*}$ in the path length of $0.5 \mathrm{~mm}$ and $1.0 \mathrm{~mm}$ for $\mathrm{HbO}_{2}$ and $\mathrm{Hb}$ indicate and justify that the method-proposed gives the difference in colour values of $\mathrm{HbO}_{2}$ and $\mathrm{Hb}$. The measured CIE L*a*b* values also show the dependency on the path length. 


\section{CONCLUSION}

The study suggests that quantification of CIE $\mathrm{L}^{*} \mathrm{a}^{*} \mathrm{~b}^{*}$ colour values for cyanosis skin colouration holds promise as a simple, practical and objective approach to more reliably document cyanosis skin, particularly for improving the skill of assessing and managing a newborn baby based on the skin colour's appearance for new medical trainees. This study highlights two significant clarification types: first, the $\mathrm{HbO}_{2}$ colouration is more red (bright red) than the $\mathrm{Hb}$ colouration, while the $\mathrm{Hb}$ blood's colour is less saturated and darker red than $\mathrm{HbO}_{2}$ blood. Second, the cyanosis colouration can be quantified, both in CIE $1931 x y$ and CIE L*a* $\mathrm{b}^{*}$. Thirdly, a colour changing actuator for a cyanosis baby manikin using the modelling proposed in this study will be constructed in that direction.

Looking back, a mechanism of colour change in baby skin based on the properties of $\mathrm{HbO}_{2}$ and $\mathrm{Hb}$ was described by taking the properties of the human visual system into account. Several simplifying assumptions also were made along the way. To calculate the resulting colours, the integration of spectral data, light, absorbance, transmission, reflection, and eyes' sensitivity which are not just triples of red, green, and blue values, but essentially also functions of the wavelength, $\lambda$ was carried out. In conclusion, there are two positions in the CIE $\mathrm{L}^{*} \mathrm{a}^{*} \mathrm{~b}^{*}$ colour space, one for the non-cyanotic oxygenated baby skin and one for the cyanotic deoxygenated. There are subtle shifts in chromaticity and brightness: the oxygenated baby skin is more red-like and more bright. Overall, the results from this paper gave a first impression of colour changes to be implemented in the future cyanosis baby manikin for clinical education and training.

\section{ACKNOWLEDGEMENT}

The author would like to acknowledge the Future Everyday Group, Industrial Design Department, Eindhoven University of Technology for their excellent support throughout this research activity. The acknowledgement also for Dr Peter Andriessen and the neonatal intensive care unit team of Máxima Medical Centre for the support and contribution towards this project. This research was supported by Pusat Pengurusan Penyelidikan Dan Inovasi (CRIM), Universiti Teknikal Malaysia Melaka.

\section{REFERENCES}

[1] S. B. Oetomo, W. Chen, and L. Feijs, "Neonatal monitoring: Current practice and future trends," in Handbook of research on developments in e-health and telemedicine: technological and social perspectives, IGI global, pp. 939-961, 2010, doi: 10.5772/10.4018/978-1-4666-0975-4.ch001.

[2] P. J. F. Peters, "Baby simulator: design of a premature baby manikin," Project: Medical Simulations, Technische Universiteit Eindhoven, 2014.

[3] M. Thielen, "ReVive: designing the newborn life support manikin," Future Everyday, Technische Universiteit Eindhoven, 2019.

[4] N. F. Azmi, "Designing Colour Changing Actuation for Realistic Cyanosis in a Baby Manikin," Future Everyday, Technische Universiteit Eindhoven, 2021.

[5] P. Pahal and A. Goyal, "Central and Peripheral Cyanosis," In: StatPearls [Internet]. Treasure Island (FL): StatPearls Publishing, 2019. Accessed Dec. 15, 2019. [Online]. Available from: https://www.ncbi.nlm.nih.gov/books/NBK559167/

[6] N. F. B. Azmi, F. Delbressine, L. Feijs, and S. B. Oetomo, "Color correction of baby images for cyanosis detection," Annual Conference on Medical Image Understanding and Analysis, vol. 894, pp. 354-370, 2018, doi: 10.1007/978-3-319-95921-4_33.

[7] L. ST Bartholomew's Hospital, "Infant suffering from cyanosis." Accessed Dec. 15, 2019. [Online]. Available: https://www.sciencephoto.com/media/252318/view

[8] S. Mukherjee, "E. Clinical Approach to Cyanosis," in Clinical Methods in Respiratory Medicine, By Jyotirmoy Pal, Supriya Sarkar, Sekhar Chakraborty., pp. 76-82, 2018.

[9] A. Adeyinka and N. P. Kondamudi, "Cyanosis," StatPearls, StatPearls Publishing, 2018. Aaccessed Feb. 25, 2019. [Online]. Available: https://europepmc.org/article/NBK/nbk482247

[10] A. Yamamoto, N. Burioka, A. Eto, T. Amisaki, and E. Shimizu, "Usefulness of pulse oximeter that can measure SpO2 to one digit after decimal point," Yonago Acta Medica, vol. 60, no. 2, pp. 133-134, 2017.

[11] E. C. Eichenwald, "Overview of cyanosis in the newborn," UpToDate, 2020. Accessed Feb. 01, 2021. [Online]. Availabe: https://www.uptodate.com/contents/overview-of-cyanosis-in-the-newborn

[12] P. S. Rao, "Neonatal cardiac emergencies: Management strategies," A Multidisciplinary Approach to Perinatal Cardiology, vol. 1, p. 447,2021

[13] P. Peters, F. Delbressine, and L. Feijs, "Designing preterm neonatal cyanosis simulation," Proceedings IWBBIO 2014, 2014, pp. 1325-1337.

[14] N. F. Azmi, F. Delbressine, and L. Feijs, "Conceptual Determination and Assessment of Cyanosis," International Journal of Bioscience, Biochemistry and Bioinformatics, vol. 6, no. 3, pp. 75-83, 2016, doi: 10.17706/ijbbb.2016.6.3.75-83.

[15] Precise color communication: color control from perception to instrumentation, Osaka, Japan: Konica Minolta, 2007.

[16] A. N. Fatihah, F. Delbressine, L. Feijs, and M. D. P. Andriessen, "Exploring Colour Change Properties in 3D Print Photochromic PLA: towards Designing Central Cyanosis Actuator in a Baby Manikin," IOP Conference Series: Materials Science and Engineering, vol. 834, no. 1, p. 012079, 2020, doi: 10.1088/1757-899X/834/1/012079. 
[17] J. Baudin, J. M. Angueyra, R. Sinha, and F. Rieke, "S-cone photoreceptors in the primate retina are functionally distinct from L and M cones,” Elife, vol. 8, p. e39166, 2019, doi: 10.7554/eLife.39166.001.

[18] C. V. R. L. Color, "Vision database at the Institute of Ophthalmology in London," 2003.

[19] M. Melgosa, Standard colorimetry: definitions, algorithms and software. Oleari, Claudio Chichester: John Wiley \& Sons, 2016, pp. 531-532, doi: 10.1002/col.22134.

[20] S. J. Dain, "Recognition of simulated cyanosis by color-vision-normal and color-vision-deficient subjects," in Journal of the Optical Society of America A, vol. 31, no. 4, pp. A303-A306, 2014, doi: 10.1364/JOSAA.31.00A303.

[21] “Useful Color Data: D65.” Accessed Apr. 31, 2017. [Online]. Available: www.rit-mcsl.org/UsefulData/all_1nm_data.xls

[22] U. Rubins, Z. Marcinkevics, J. Cimurs, A. Grabovskis, and E. Kviesis-Kipge, "Snapshot hyperspectral system for noninvasive skin blood oxygen saturation monitoring," in Proceedings Volume 10685, Biophotonics: Photonic Solutions for Better Health Care VI, 2018, vol. 10685, p. 106853Y, doi: 10.1117/12.2306985.

[23] S. Prahl, "Optical absorption of hemoglobin," 1999. Accessed Mar. 22, $2017 . \quad[$ Online]. Available: http://omlc.ogi.edu/spectra/hemoglobin

[24] Y. A. Pinar, O. Bilge, and F. Govsa, "Anatomic study of the blood supply of perioral region," Clinical Anatomy, vol. 18, no. 5, pp. 330-339, 2005, doi: 10.1002/ca.20108.

[25] J. Schanda, Colorimetry: understanding the CIE system. John Wiley \& Sons, 2007.

[26] M. J. Delgado-González, Y. Carmona-Jiménez, M. C. Rodríguez-Dodero, and M. V García-Moreno, "Color space mathematical modeling using Microsoft Excel,” J. Chem. Educ., vol. 95, no. 10, pp. 1885-1889, 2018, doi: 10.1021/acs.jchemed.7b00681.

\section{BIOGRAPHIES OF AUTHORS}

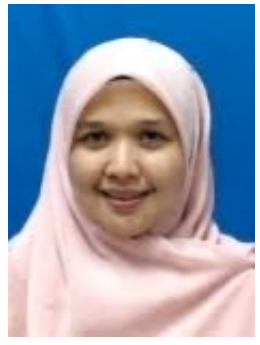

Nur Fatihah Azmi (D) S P obtained her first Bachelor of Engineering in the Department of Electronics and Computer System in 2008 from Takushoku University in Tokyo, Japan. She continued her study in the same lab in Electronics and Information Science (Master of Engineering) also from Takushoku University, Tokyo. In 2010, she joined Universiti Teknikal Malaysia Melaka as a lecturer at the Faculty of Electronic \& Computer Engineering. In May 2021, she obtained her PhD degree in the Industrial Design Department at Eindhoven University of Technology (TU/e) in the Netherlands. Her research area is neonatal monitoring and baby manikin simulation especially in developing the colour changing of cyanosis actuator for medical simulation application. She can be contacted at email: fatihah@utem.edu.my.

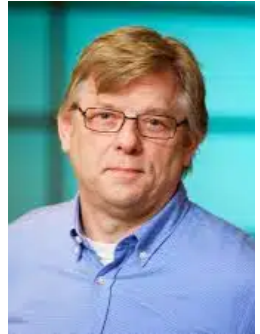

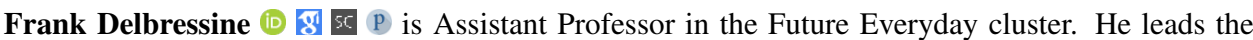
Medical Simulation laboratory, the Mobility Laboratory and the Neonatal Simulation lab. Delbressine is interested in Smart Mobility and in Health-related industrial design. He is especially interested in design for Autonomous Vehicles and Medical Simulation. He has a background in mechanical design, engineering and manufacturing. Delbressine has authored or co-authored around 40 papers on mechanical design, precision engineering, medical simulation and smart mobility. He currently coaches $6 \mathrm{PhD}$ students. He has organized a large conference on Precision Engineering and is author or co-author of three patents. He can be contacted at email: fdelbres@tue.nl.

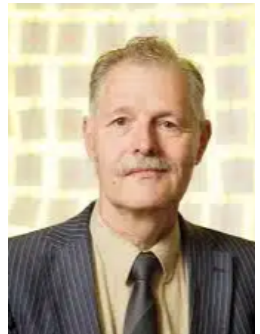

Loe Feijs (D) 5 ( 5 received the M.Sc. degree in electrical engineering and the Ph.D. degree in computer science from the Eindhoven University of Technology, Eindhoven. In the 1980s, he was involved in video compression and telephony systems. He joined Philips Research to develop formal methods for software development. He became a part-time Professor of mathematics and computer science in 1994, the Scientific Director of the Eindhoven Embedded Systems Institute in 1998, and the Vice Dean of the Department of Industrial Design, Eindhoven University of technology, in 2000. $\mathrm{He}$ is currently a Professor of industrial design with the Eindhoven University of Technology. $\mathrm{He}$ has authored three books on formal methods and over 200 scientific papers. His current research interests include creative programming, design of wearable systems, and biofeedback systems. He can be contacted at email: 1.m.g.feijs@tue.nl. 